\title{
Investigation of Neem Fatty Acid Ethyl Ester for Electric Power Generation
}

\author{
G. Vijaya Gowri, M. Kannan, A. Murugesan \\ Department of Electrical \& Electronics, Engineering K. S. Rangasamy College of Technology, India
}

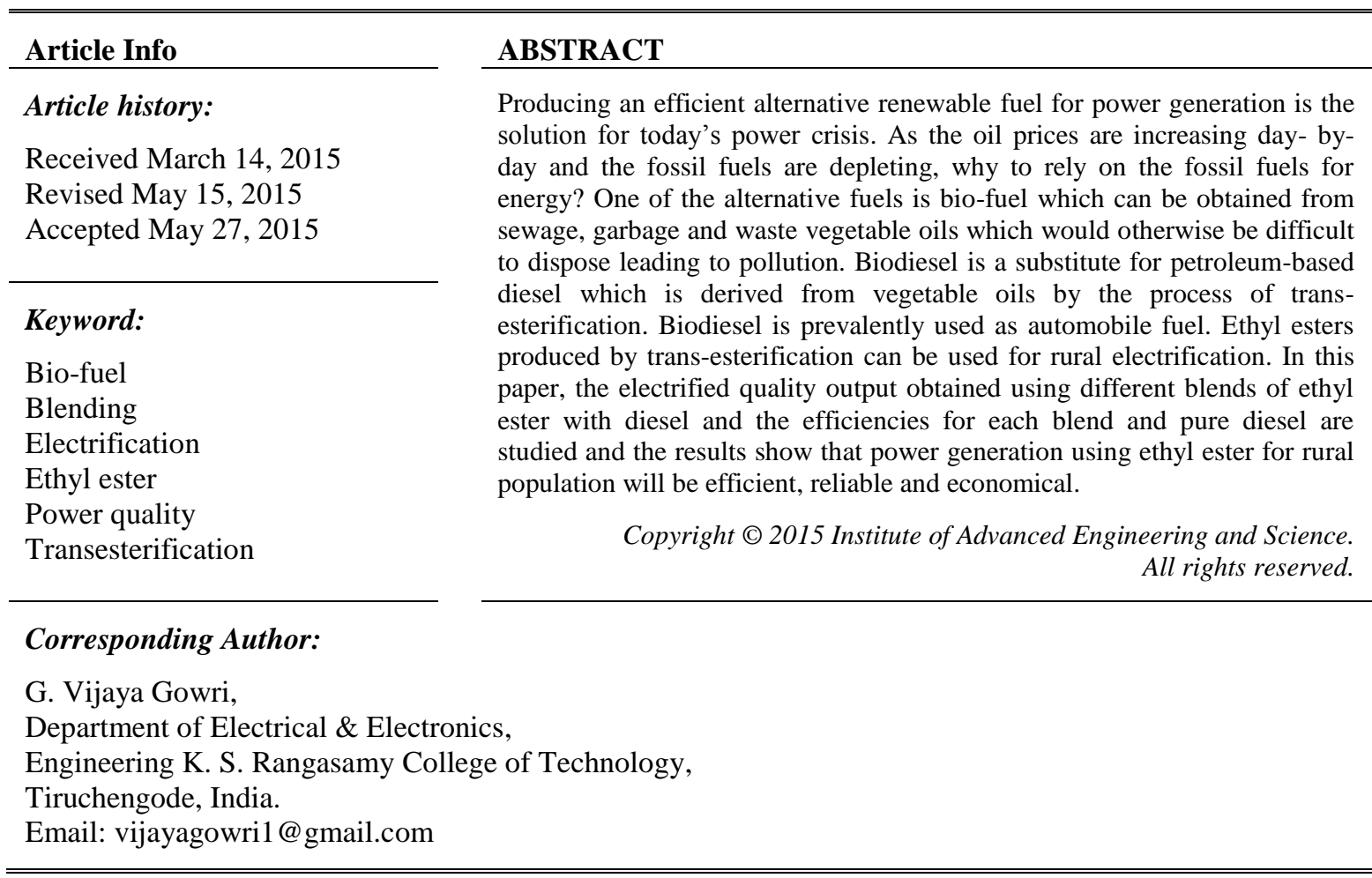

\section{INTRODUCTION}

Most of the nations world around are well developed and the main criteria for utilising the innovative appliances efficiently and for more technical developments is the reliable electric power supply. Fossil fuels added its value in providing surplus electric energy till this decade. However, due to the depletion in the fossil fuels and the growing demand with the increase in population and scientific and technical developments, the amount of electric power from the fossil fuels is insufficient. In a nation like India with agriculture as its backbone, electricity and water are much more essential. The demand for power is increasing day-by-day which has led us to seek an alternative source to overcome a part of power crisis. There are renewable sources such as solar energy, wind energy, tidal energy, geo-thermal energy and biomass which have their own advantages and disadvantages. Crude oil reserve can last for only 20 years. Foreseeing the advantages of these renewable energy sources, a part of the demand can be met. There is also a renewable source which is eco-friendly and produced from vegetable oils and animal fats.

India is the world's $6^{\text {th }}$ largest consumer of energy about $3.6 \%$ of global consumption. The average demand has grown up to $3.6 \%$ per annum over the past 30 years [1]. The India's demand is mainly met through coal reserves accounting to 50\% [2]. The energy consumed in India is from thermal plants (about $76 \%$ ), hydro power $(21 \%)$ and $4 \%$ nuclear plant. Wind energy contributes to some extent. Due to the shortage of electricity, power cuts are common throughout India and this has affected India's economic growth.

In Tamilnadu a minimum of two hours per day power cut is prevailing. There are also villages in India which are still out of reach from electricity. Industries need more reliable source of energy. For this reliable energy, they depend on co-generation plants or captive generation plants within their own campuses. 
But these co-generation and captive plants don't satisfy the demand of a nation. Biodiesel is a source obtained from vegetable oils, animal fats and waste cooking oils. It is a secured and self reliant fuel. It reduces carbon and sulphur emissions [3], [4]. The properties of biodiesel are similar to that of petroleum diesel [5]. It can be used as a fuel to produce electricity [6], [7]. If biodiesel plants are installed, there will be employment opportunities from workers to engineers. Life becomes miserable without sufficient supply of electric energy. Each and every house is lit by electricity except few thousands of villages which are still not electrified. Also, establishing a biodiesel plant in a rural area benefits the farmers much by providing biodiesel, an efficient fuel for irrigation and oil cakes rich in nitrogen as fertilizer to improve the growth. The villagers get employed and the farmers can cultivate and use their own raw materials for oil production thereby developing themselves economically [8]. Biodiesel electrification facilitates local employment and self-development opportunities among rural mass.

\section{CHEMISTRY OF BIODIESEL}

Biodiesel is a renewable fuel and can be plant derived, animal derived, microbial or from waste materials. It is an alternative to petroleum-based diesel. Biodiesel contains no sulphur content in it. So, it burns cleaner than conventional diesel [9]. Refined biodiesel consists mainly of fatty esters, (FFA) Free Fatty Acids and some triglycerides. Biodiesel feedstock consists of vegetable oils, animal fats and recycled grease. Plant derived oils contain high percentage of triglycerides. These triglycerides are very large molecules. Before using these oils in an internal combustion engine, these triglycerides are to be broken down to reduce their viscosity [9]. Basically, ester can be obtained from oils and fats by the following three ways. (a) Base catalyzed trans-esterification of the oil with alcohol (b) Direct acid catalyzed esterification of the oil with methanol (c) Conversion of the oil to fatty acids, and then to Alkyl esters.

The majority of the alkyl esters produced today are done with the base catalyzed reaction because it is the most economic for several reasons. (a) Processing at low temperature and pressure (b) Conversion is possible with minimal side reactions and reaction time (c) No intermediate steps during conversion [10].

\subsection{Trans-esterification Process}

Parent oil used in making biodiesel consists of triglycerides in which three fatty acid molecules are esterified with a molecule of glycerol. In making biodiesel, triglycerides are reacted with alcohol (methanol/ethanol) in the presence of base catalysts $(\mathrm{NaOH} / \mathrm{KOH})$ known as trans-esterification or alcoholysis. The use of base catalysts is because of the fact that the trans-esterification reaction is generally faster, less expensive and more complete with these materials [10]. Trans-estrification produces methyl/ethyl esters of fatty acids, ie., biodiesel, and glycerol. The reaction occurs stepwise: triglycerides are first converted to diglycerides, then to monoglycerides and finally to glycerol [11], [12]. The trans-esterification reaction involves three steps. These steps are shown in Equation (1).

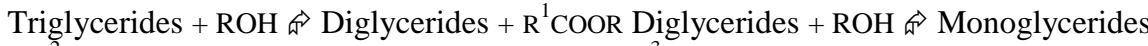

$+\mathrm{R}^{2} \mathrm{COOR}$ Monoglycerides $+\mathrm{ROH}$ 的 Glycerol $+\mathrm{R}^{3} \mathrm{COOR}$

\subsection{Procedure for Trans-esterification}

1. The amount of water and free fatty acids present in the oil should not be high. If so, it will lead to saponification and difficulty in glycerin separation [13].

2. Catalyst $(\mathrm{NaOH} / \mathrm{KOH})$ is dissolved in the alcohol(ethanol/methanol) using a standard agitator or mixer. The purity of $\mathrm{NaOH}$ is higher than that of $\mathrm{KOH}$ [4] Excess or insufficient amount of catalyst also leads to saponification [11].

3. The alcohol/catalyst mix is then charged into a closed reaction vessel and the vegetable oil is added. The vessel is closed to prevent the loss of alcohol.

4. The reaction mix is kept at $72^{\circ} \mathrm{C}$, which is just above the boiling point of alcohol. It is only to speed up the reaction. The reaction time is 8 hours. The optimal temperature for this reaction lies within the range of $50 \pm 5^{\circ} \mathrm{C}$.

5. Glycerin, much denser than bio-diesel settles down the vessel and can be separated.

6. Then the excess alcohol is removed by distillation.

7. The glycerin by-product contains unused catalyst and soaps that are neutralized with an acid which is crude glycerin.

\subsection{Experiment}

Neem oil is pretreated to remove excess FFA and moisture content from it. Neem oil is mixed with 
water in a proportionate quantity. The mixture is agitated and air bubbles are passed through the mixture to remove the fat content from the oil. The fat extracted neem oil is heated to a temperature of $100^{\circ} \mathrm{C}$ to remove the hydrated form of oxygen from it. Then it is allowed to cool. This partially purified neem oil is mixed with ethanol and potassium hydroxide in suitable amount. In this alcohol catalyst reaction, the alcohol used is ethanol and the catalyst is potassium hydroxide. This mixture is agitated thoroughly using a motor in a chamber for ninety minutes at a temperature of $73^{\circ} \mathrm{C}$. High reaction temperature will increase the bio-diesel production cost. The chamber and the process kit is shown in Figure 1. The final products obtained in this process are bio-diesel and glycerol. Glycerine, which is heavier than monoalkyl esters deposits at the bottom as shown in Figure 2 and it is then separated.

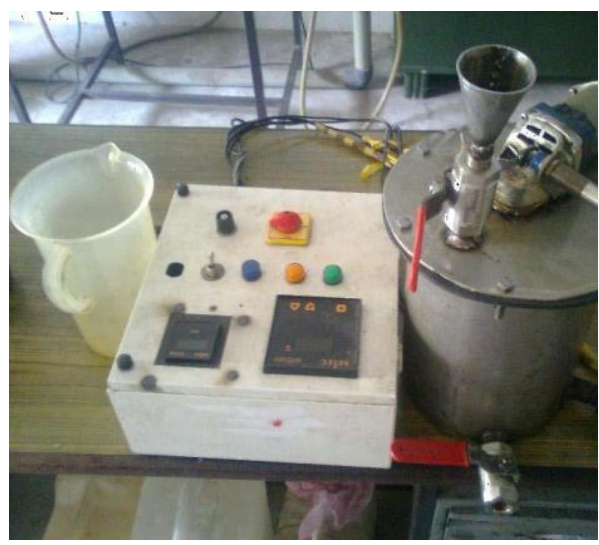

Figure 1. Transesterification Kit

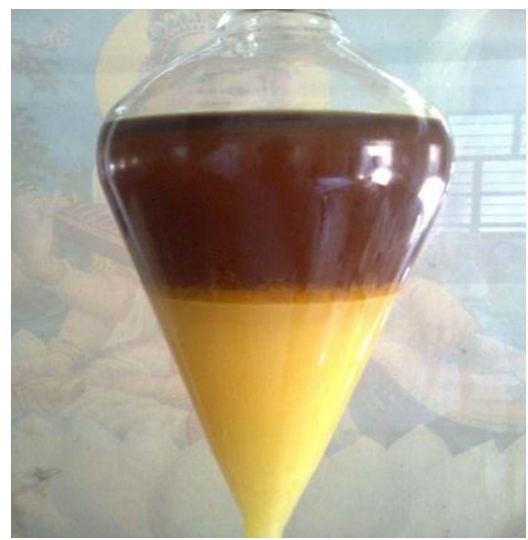

Figure 2. Bio-diesel and Glycerol Mixture

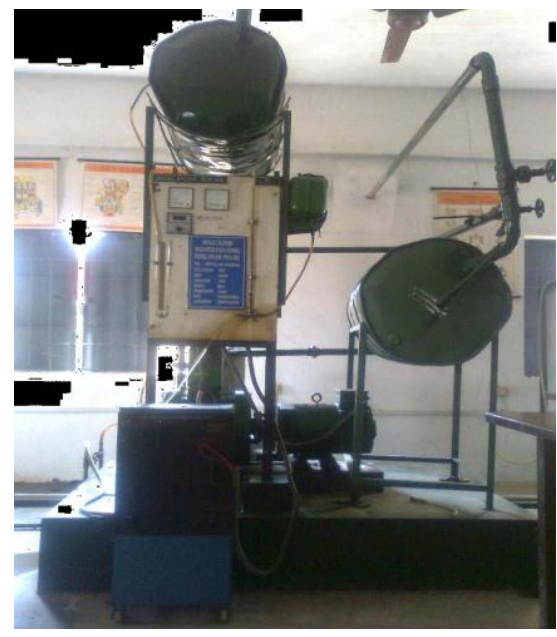

Figure 3. Experimental Setup

The bio-diesel is then heated and allowed to cool. This entire process is called trans-esterification. Pure biodiesel is called B100. The use of B100 reduces the emissions of greenhouse gases and other toxic gases, but can lead to increase in nitrogen oxide emissions [14]. So, bio-diesel obtained is blended with diesel in suitable proportion for efficient and healthy use. It is then electrified using diesel engine coupled to an alternator. The entire experimental setup is shown in Figure 3. The engine used is Kirloskar Diesel Engine. Electrical power is generated and it is given to a resistive load. In the process of generating electricity, initially the diesel engine is made to run in diesel fuel. The alternator is coupled with diesel engine. The set up consists of engine, alternator and resistive load. The engine and the alternator specifications are given in Table 1 and Table 2.

The load connected is $3 \Phi$ resistive load. The three phase total power with either star-connected or delta- connected load is given by Equation (2). 
Power, $P=3 \operatorname{VICos} \Phi(K W)$

Where, $\mathrm{V}-$ Voltage $=390 \mathrm{~V}$

Power $=3.7 \mathrm{KW}$

Table 1. Alternator Specifications

\begin{tabular}{cl}
\hline Parameters & Rating \\
\hline KVA rating & 5 \\
No. of Phases & 3 \\
Speed & $1500 \mathrm{RPM}$ \\
Frequency & $50 \mathrm{~Hz}$ \\
Voltage rating & $230 / 450 \mathrm{~V}$ \\
\hline
\end{tabular}

Table 2. Engine Specifications

\begin{tabular}{ll}
\hline Parameters & Ratings/Methods \\
\hline Horse power & 5 \\
Power Rating & $3.7 \mathrm{KW}$ \\
Cooling method & Water cooling \\
Loading method & Resistive loading \\
Engine Orientation & Vertical \\
No. of cylinders & 1 \\
No. of strokes & 4 \\
\hline
\end{tabular}

The current for different percentage of loads are calculated and are shown in the Table 3, Table 4, and Table 5.

Table 3. 80\% Diesel-20\% Bio-diesel

\begin{tabular}{cccccc}
\hline S. No & Load $(\mathbf{K W})$ & \% of Load & Actual Voltage (Volts) & Calculated Current (Amps) & Actual Current (Amps) \\
\hline 1 & 0.00 & 0 & 390 & 0.0 & 0.0 \\
2 & 0.50 & 40 & 390 & 2.19 & 1.7 \\
3 & 0.75 & 60 & 391 & 3.29 & 2.8 \\
4 & 1.00 & 80 & 397 & 4.38 & 3.9 \\
5 & 1.25 & 100 & 400 & 5.48 & 5.2 \\
\hline
\end{tabular}

Table 4. 20\% Diesel-80\% Bio-diesel

\begin{tabular}{cccccc}
\hline S. No & Load $(\mathbf{K W})$ & \% of Load & Actual Voltage (Volts) & Calculated Current (Amps) & Actual Current (Amps) \\
\hline 1 & 0.00 & 0 & 390 & 0.0 & 0.0 \\
2 & 0.50 & 40 & 390 & 2.19 & 2.0 \\
3 & 0.75 & 60 & 395 & 3.29 & 3.0 \\
4 & 1.00 & 80 & 395 & 4.38 & 4.2 \\
5 & 1.25 & 100 & 400 & 5.48 & 5.2 \\
\hline
\end{tabular}

Table 5. Pure diesel

\begin{tabular}{cccccc}
\hline S. No & Load $(\boldsymbol{K W})$ & \% of Load & Actual Voltage (Volts) & Calculated Current (Amps) & Actual Current (Amps) \\
\hline 1 & 0.00 & 0 & 390 & 0.0 & 0.0 \\
2 & 0.50 & 40 & 390 & 2.19 & 1.8 \\
3 & 0.75 & 60 & 393 & 3.29 & 3.0 \\
4 & 1.00 & 80 & 400 & 4.38 & 4.1 \\
5 & 1.25 & 100 & 5.48 & 5.2 \\
\hline
\end{tabular}

\section{RESULTS AND DISCUSSION}

The biodiesel was produced and mixed in proper proportions with pure diesel for the study. Initially, the engine was run with pure diesel. An output voltage of about $390 \mathrm{~V}$ to $400 \mathrm{~V}$ was experienced. Variation in current due to the change in load was found. The maximum efficiency is found to be $56.22 \%$ 
with the maximum brake power of $3.7 \mathrm{KW}$. Similarly, the analysis was carried out for $20 \%$ biodiesel $80 \%$ pure diesel blends and $80 \%$ biodiesel $-20 \%$ pure diesel blends. Here again the maximum efficiency was obtained and found to be same as that of pure diesel. The characteristics of the output voltage, current and efficiency are shown in Figure 4, Figure 5 and Figure 6 respectively. The maximum output power of $2 \mathrm{KW}$ was obtained. Also, the experiment shows that the quality of power is not affected by the quality of biodiesel. The biodiesel production is affected by the reaction temperature, reaction rate and the amount of moisture content. The analysis shows that B80 gives better efficiency with the change in load.

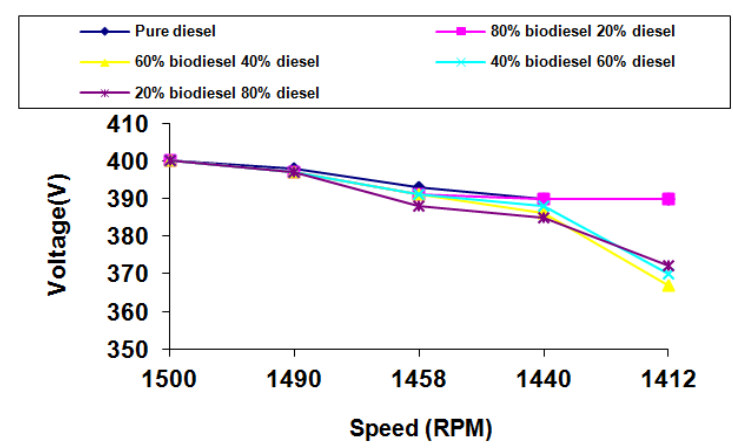

Figure 4. Speed vs Voltage Characteristics of Alternator
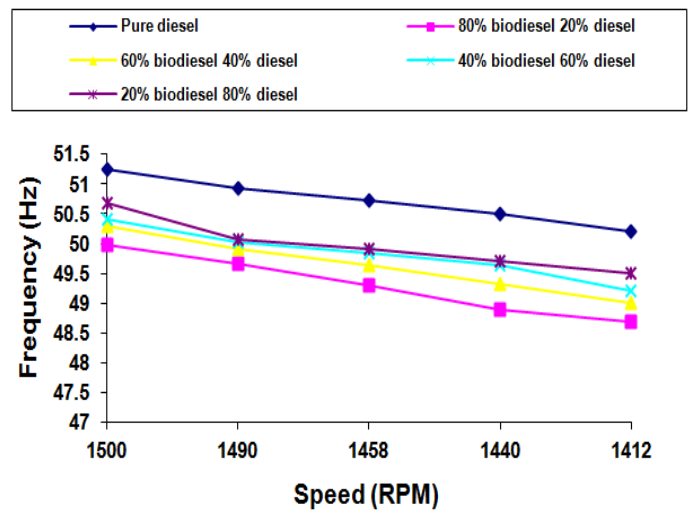

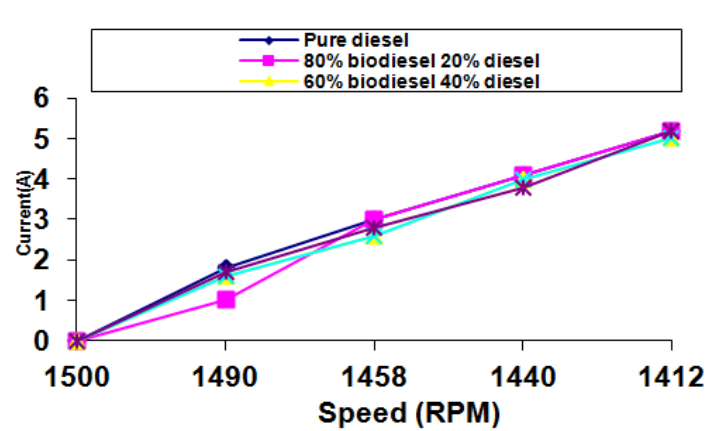

Figure 5. Speed vs Current Characteristics Alternator

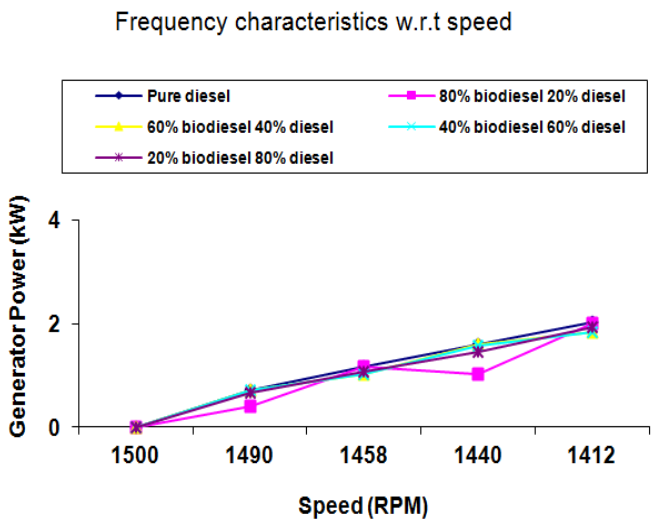

Figure 6. Brake Power vs Generator Power Characteristics of Alternator Run by using Ethanolised Biodiesel

It is analyzed that the voltage generated and the corresponding current produced is approximately the same in all the three cases. The mixture of $20 \%$ of biodiesel and $80 \%$ of petroleum diesel is called B20. Previous studies on bio-diesel blends show that the energy content of biodiesel is lesser than petroleum diesel, which affects the engine performance with the increase in the content of biodiesel. Therefore, the proportion of biodiesel with the petroleum diesel must be less. The voltage profile for pure bio -diesel, $80 \%$ diesel - 20\% bio-diesel and 20\% diesel - $80 \%$ biodiesel are shown in Table 6 . The characteristics demonstrate the effect of bio -diesel on electrical output. There is no indication of difference in voltage generation for pure diesel and other blends shown above. The efficiency for pure diesel and two different blends are tabulated in Table 7. The advantage lies in the fact that it is renewable energy source with less pollution and environment healthy. The quality of power obtained will be without harmonics. Different research works has been already carried out on engine performance stating that B20 works well with better efficiency [1], [12]. When the performance of the engine is better, it is acceptable that the electrical output will be continuous without any hindrance. 
Table 6. Voltage Profile

\begin{tabular}{ccccc}
\hline \multirow{2}{*}{ S.No } & Load (KW) & & \multicolumn{2}{c}{ Voltage (Volts) } \\
& Pure Diesel & 80\% Diesel- 20\% Bio-Diesel & 20\% Diesel- 80\% Bio-Diesel \\
\hline 1 & 0.00 & 385 & 385 & 372 \\
2 & 0.50 & 390 & 390 & 386 \\
3 & 0.75 & 395 & 393 & 391 \\
4 & 1.00 & 395 & 398 & 397 \\
5 & 1.25 & 405 & 400 & 400 \\
\hline
\end{tabular}

Table 7. Efficiency Calculation

\begin{tabular}{|c|c|c|c|c|c|c|c|}
\hline \multirow[b]{2}{*}{ S.No } & \multirow[b]{2}{*}{$\begin{array}{c}\text { Brake Power } \\
(\mathrm{KW})\end{array}$} & \multicolumn{3}{|c|}{ Generator Power (KW) } & \multicolumn{3}{|c|}{ Generator Efficiency (\%) } \\
\hline & & Pure Diesel & $\begin{array}{c}80 \% \text { Diesel- } \\
\text { 20\% Bio- } \\
\text { Diesel }\end{array}$ & $\begin{array}{c}20 \% \text { Diesel- } \\
\text { 80\% Bio- } \\
\text { Diesel }\end{array}$ & Pure Diesel & $\begin{array}{c}80 \% \text { Diesel- } \\
\text { 20\% Bio- } \\
\text { Diesel }\end{array}$ & $\begin{array}{c}20 \% \\
\text { Diesel- } \\
80 \% \text { Bio- } \\
\text { Diesel }\end{array}$ \\
\hline 1 & 0.00 & 0.00 & 0.00 & 0.00 & 0.00 & 0.00 & 0.00 \\
\hline 2 & 1.479 & 0.702 & 0.663 & 0.78 & 47.46 & 44.83 & 52.47 \\
\hline 3 & 2.222 & 1.179 & 1.095 & 1.185 & 53.06 & 49.28 & 53.33 \\
\hline 4 & 2.986 & 1.632 & 1.548 & 1.659 & 54.66 & 51.84 & 55.56 \\
\hline 5 & 3.7 & 2.080 & 2.080 & 2.080 & 56.22 & 56.22 & 56.22 \\
\hline
\end{tabular}
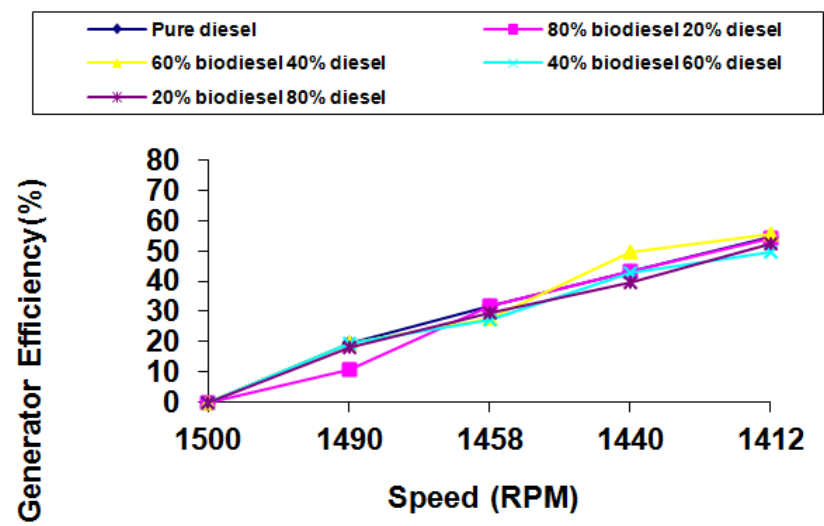

Figure 7. Brake Power vs Generator Efficiency Characteristics of Alternator Run by using Ethanolised Biodies

\section{CONCLUSION}

The following conclusions are made from the experimental result.

1. Neem oil methyl esters are a renewable energy source for efficient power generation.

2. Continuous supply of energy can be obtained with neem oil ethyl esters as a source with a maximum efficiency of $56.22 \%$. biodiesel.

3. The generated voltage is within a narrow range between $390 \mathrm{~V}$ and $400 \mathrm{~V}$ for various blends of

4. Power generated will be without harmonics.

Hence, the environmentally healthy and eco-friendly neem oil ethyl ester can be used to generate quality power to improve Indian economy.

\section{REFERENCES}

[1] Indian Power Sector, “A comprehensive analysis," Managerial Economics Final Project Report, FORE School of Management, FMG XVIII A. 2009.

[2] R. V. Shahi, "Keynote Address on Energy Markets and Technologies in India", In Global Energy Dialogue at Hanover (Germany), April 2006.

[3] T. Venkateswara Rao, G. Prabhakar Rao and K. Hema Chandra Reddy, "Investigation of Pongamia, Jatropha and Neem Methyl Esters as Biodiesel on C.I. Engine”, Jordan Journal of Mechanical and Industrial Engineering, Vol. 2, No. 2, pp. 117-122, June 2008.

[4] Md. Nurun Nabi, Johan Einar Hustad, and Dhandapani Kannan, "First Generation Biodiesel Production from Non 
Edible Vegetable Oil and Its Effect on Diesel Emissions", Proceedings of the 4th BSME -ASME International Conference on Thermal Engineering, December 2008.

[5] A. S. Ramadhas, S. Jayaraj, and C. Muraleedharan, "Theoretical modeling and experimental studies on biodieselfueled engine".

[6] Anil K. Rajvanshi, "Electricity and Water Revolution in Rural Areas", Editorial article in Times of India, July 2005.

[7] Jeffrey L. Rosenblum, "Feasibility of biodiesel for rural electrification in India", June 2000.

[8] Government of India, Ministry of New \& Renewable Energy, "National Policy on Biofuels".

[9] Sheraz Abbasi, "Stochastic modeling of biodiesel production process", Urmila Diwekar University of Illinois Chicago.

[10] Bryan R. Moser, "Biodiesel production, properties, and feedstocks", The Society for In Vitro Biology, 2009.

[11] A. Murugesan, C. Umarani, T. R. Chinnusamy, M. Krishnan, R. Sbramanian, N. Neduzchezhian, "Production and analysis of bio-diesel from non-edible oils-A review", Renewable and sustainable energy reviews, Vol. 13, pp. 825834, 2009.

[12] Yusuf Chisti, "Biodiesel from microalgae", Biotechnology Advances, Vol. 25, pp. 294-306, 2007.

[13] A. E. Ghaly, D. Dave, M. S. Brooks, "Production of Biodiesel by Enzymatic Transesterification: Review", American Journal of Biochemistry and Biotechnology, Vol. 6, No. 2, pp. 54-76, 2010.

[14] Meda Chandra Sekhar, Venkata Ramesh Mamilla, M. V. Mallikarjun, and K. Vijaya Kumar Reddy, "Production of Biodiesel from Neem Oil”, International Journal of Engineering Studies, Vol. 1, No. 4, pp. 295-302. 